\title{
Trust and safety onboard
}

\author{
Anne H. Gausdal ${ }^{1}$ • Julija Makarova ${ }^{1}$
}

Received: 14 December 2015 / Accepted: 30 March 2017 /Published online: 12 April 2017

C The Author(s) 2017. This article is published with open access at Springerlink.com

\begin{abstract}
Shipping is a high-risk industry. The aims of this conceptual paper are to build a framework showing in what way safety onboard is influenced by trust, and to identify the main obstacles to trust-building within the shipping industry. To meet these aims, a literature review and a pilot study are conducted. The study shows that interpersonal trust from employees to managers, and among seafarers, seems to be a prerequisite and an indirect factor, or mediating variable, that influence safety-related organizational outcomes positively and seems to reduce human errors. Interpersonal trust seems to be most valuable in weak situations, which means situations that are not critical and when no exact guidance or incentives to behave in a particular way are needed. An optimal level of trust exists onboard, and because of the high-risk environment, this optimal level of trust is expected to be relatively high. The main obstacles to trust within the shipping industry seem to be the dual employment practice, the physical distance between onboard, crewing agency and onshore, the reduced competence requirements, the frequent reorganization of the crew and multiculturalism. The paper contributes to the trust and to the safety literature by a new framework and to the development of 11 hypotheses on trust and safety. Finally, the paper is indicating that trust may be the missing piece in the safety puzzle.
\end{abstract}

Keywords Interpersonal trust $\cdot$ Safety $\cdot$ Obstacles to trust $\cdot$ Shipping industry

\section{Introduction}

Shipping is considered as a high-risk industry, and working in this industry is recognized as one of the most dangerous occupations (Nielsen 1999). Even if the industry has been improving the reliability of the ship systems in order to reduce accident rate

Anne H. Gausdal

ang@usn.no

1 Department of Maritime Operations, Faculty of Technology, Natural Sciences and Maritime Sciences, University College of Southeast Norway, Postbox 4, Borre No-3199, Norway 
and increase efficiency, the accident rate is still high (Rothblum et al. 2002), and, e.g. the number of ship accidents in Norway has increased 5.2\% from 2010 to 2015 (Norwegian_maritime_authority 2016). Increased safety in the shipping industry is therefore of great concern.

Trust is called the missing piece in the safety puzzle, and the importance of trust with respect to safety has long been recognized by practitioners (Conchie et al. 2006), and has lately also been acknowledged by researchers. Trust is, among other factors, found to facilitate open and safety communication (Reason 1998), to promote effective safety leadership (Conchie and Donald 2006) and to be a major aspect of accuracy of work (Galford and Drapeau 2002). Interpersonal trust affects knowledge sharing and learning (Matzler et al., 2011) and enables organizations to capture, reuse and share information and lessons learned from past mistakes with employees and newcomers (Dirks 2000).

In addition to the high-risk implications, the shipping industry has some particular characteristics that may influence trust-building like, for example, physical distance and a lack of face-to-face communication. The management of the companies works onshore at the office, while the crew works offshore on the ships. It is common to re-organize the crew between each voyage and to outsource the manning of the ships to crewing agencies in third world countries (Berg et al. 2013). About 70-80\% of the global fleet has multicultural crew, and subordinate crews often work on less favorable conditions than the officers (Berg et al. 2013).

Although some researchers have studied the impact of trust on safety culture within high-risk industries (e.g. Conchie et al. 2006; Reason, 1998), few studies are concerned with the influence of trust on safety within the shipping industry: "Trust remains a neglected area of empirical investigation" (Conchie and Donald 2006, p. 1098), and most of the existing studies are quantitative. This conceptual paper aims to contribute in filling these gaps through the following research question: In what way is safety on board influenced by trust, and what are the main obstacles to trust-building within the shipping industry? To answer this question, a literature review and a pilot study in the form of a qualitative case study within a Norwegian shipping company have been conducted. Moreover, a framework has been devised to illustrate how safety onboard is influenced by trust, and to identify the main obstacles to trust within the shipping industry.

The paper is organized as follows: After an introductive section (Section 1), Section 2 provides the literature review, while the research methods and the case description are presented in Section 3. Section 4 illustrates the findings, which is then discussed in Section 5. Section 5 also presents the framework, while Section 6 contains some concluding remarks.

\section{Literature review}

\subsection{What is trust?}

Trust is a multi-level, multi-dimensional and dynamic concept. The emphasis in this paper is on interpersonal trust. Different approaches to trust exist, and the vast literature holds, e.g. vulnerability, risk, cognition, affect, competence, reliability, integrity and suspension, as central trust concepts (Zand 2016). Ring and Van de Ven (1994) 
differentiate between fragile and resilient forms of trust. Zucker (1986) suggest three dimensions of trust related to different modes of trust production; institution-based, characteristic-based and process-based. McAllister (1995) distinguish between affective- and cognition-based trust, and similarly, Abrams et al. (2003) distinguish between competence-based and benevolence-based trust. Moreover, in a comprehensive review of trust antecedents, Mayer et al. (1995) identified the three main dimensions of trust: ability, benevolence and integrity.

Some theorists, e.g. Rotter (1971), see interpersonal trust as a relatively stable personality characteristic. Social psychologists, however, view trust as a transactional-related expectation with vulnerability as a key element, and being able, willing and consistent in not exploiting vulnerability is a common feature for the different frameworks for interpersonal trustworthiness (Möllering 2006). In selecting among the many definitions of trust, we have therefore chosen a robust definition with focus on vulnerability and define trust with Mayer et al. (1995 p. 712) as "the willingness of a party to be vulnerable to the actions of another party based on the expectation that the other will perform a particular action important to the trustor, irrespective of the ability to monitor or control that other party". The vulnerability also points at the fact that some risk is in fact involved in the uncertainty about an outcome. We also build on the framework of cognitive and affective trust, where cognitive trust represents our choice of whom we will trust and why, while affective trust depends on our emotional bonds with another person (Lewis and Wiegert 1985; McAllister 1995).

Trust may also be seen as a pyramid of interconnected dysfunctions (Lencioni 2002), where the base of the pyramid is the absence of trust deriving from the unwillingness to make oneself vulnerable. Subsequent to the absence of trust is the fear of conflict, when people are incapable to engage in productive debates. A lack of such debate leads to a lack of commitment, as people will not commit to decisions which they personally may not agree upon, while at the same time they restrain from disclosing their own decision. Finally, failure to be accountable leads to inattention to results, where employees prioritize their individual goals rather than the goals of the team (Lencioni 2002).

\subsection{How to build interpersonal trust?}

"We choose whom we will trust in which respects and under what circumstances, and we base the choice on what we take to be 'good reasons,' constituting evidence of trustworthiness" (Lewis and Wiegert 1985, p. 970). Trust-building is normally a slow process (Zucker 1986), and in building cognitive and affective trust, interpersonal contact is required (Krogh 1998; Zucker 1986). Frequent close interactions may lead people to better understand each other's expertise and "increase[s] trust in one another's competence" and to care about each other (Abrams et al. 2003). They contribute therefore to build cognitive and affective trust. Cognitive trust is influenced by success of past interaction, ability, consistent behaviour, a reliable role performance and social, cultural or ethnical similarity (Gausdal 2012; McAllister 1995; Naphiet and Ghoshal 1998). Shared language is also important, as it seems to promote trust-building especially in terms of cognitive trust (Abrams et al. 2003; McAllister 1995). Cognitive interpersonal trust may be characteristic-based or process-based. 
Characteristic-based trust entails a recognition of each other's knowledge and experiences, along with an expectation that the other participants have something valuable to contribute. It is rooted in personal similarity and develops as people learn that they have similar cultural, educational, occupational or other practice-based backgrounds (Zucker 1986). Process-based trust is founded upon recurrent interaction; it develops gradually as people accumulate shared experiences from joint problem solving, and increases their acceptance of risk and their willingness to commit to closer forms of collaboration (Zucker 1986). Affective trust is influenced by cognitive trust, long-term cooperative actions, frequent interaction, feeling of affection, friendship and the level of citizenship behaviour directed toward you (Gausdal 2012; Krackhardt 1992; McAllister 1995). Building interpersonal trust, therefore, requires that people actually meet, get to know each other and on this basis become able to assess each other's knowledge and background. The process-based trust also requires people to interact and collaborate over time.

\subsection{How, why and when is trust important for safety onboard?}

Safety climate is the sum of workers "common perceptions regarding safety in their organization" (Zohar 1980, p. 98). Although the link between safety climate and injuries has been thoroughly examined, there is still no clear answer to this relationship (Kath et al., 2010). But in a comprehensive study of a grocery store chain, Kath et al. (2010) identified organizational trust, measured at the individual level, as a mediator of the relationship between safety climate and organizational outcome, and the influence was stronger when job safety relevance was high. Because job safety relevance is high onboard, these findings are highly relevant here. Our hypothesis (H1) is therefore that interpersonal trust may be an indirect factor, or mediating variable, influencing safetyrelated organizational outcomes positively.

Communication and cooperation are important for maritime safety (Berg et al. 2013), and leading theorists also agree that there is a connection between interpersonal trust, communication and cooperation (Dirks and Ferrin 2002; Hardin 2002).

About $80 \%$ of the accidents in the shipping industry happen due to human errors (Berg et al. 2013), which is operationalized as incorrect decision, improperly performed action or an improper lack of action (Rothblum et al. 2002). One reason for incorrect decision may be lack of knowledge sharing; one type of lack of action is not asking for advice. Interpersonal trust is considered essential in the sharing of knowledge in a reciprocal way, as it is a significant factor in sharing and absorbing tacit knowledge (Krogh et al., 2000). Such tacit knowledge is crucial for the creation of new knowledge (Nonaka 1994), and it is also an important prerequisite for asking for advice (Abrams et al. 2003). Lack of knowledge sharing and not asking for advice may be seen as minor errors, but since minor errors may lead to serious casualties (Wagenaar and Groeneweg 1987), such errors are of great interest for the purpose of safety improvement. Our hypothesis $(\mathrm{H} 2)$ is therefore that interpersonal trust may influence human errors negatively.

The effect of trust on safety may, however, be situational. Mischel (1977) distinguishes between "strong" and "weak" situations: Strong situations, e.g. when a ship is close to collision or goes alongside the port, provide guidance and incentives to behave in a particular way, and lead everyone to construe the particular events in a similar 
manner. In weak situations, e.g. sailing on high seas in good weather, no exact guidance or incentives to behave in a particular way are needed, nor clear or powerful cues that lead individuals to interpret the events in a similar manner. Dirks and Ferrin (2002) propose that trust within organizations has a significant effect in weak situations, but no effect in strong situations. In a crisis, on the other hand, people need trust in order to reduce the complexity they are facing (Luhmann 1979). Our hypothesis (H3) is therefore that interpersonal trust is positively influencing safety in weak situations.

\subsection{In what way is safety onboard influenced by trust?}

As middle managers, the company managers are identified as the most significant predictive factor for promoting a safety culture that induces safe behaviours (Wu et al. 2011). Managers' trust and concern about crew's safety, as well as active encouraging of safe behaviours, contribute to increase safety onboard (Lu and Tsai 2008). Trust enhances care for the safety of employees, and if employees trust the management, they are more likely to share the manager's opinion about the importance of safety (Luria 2010). Interpersonal trust occurs at different levels. Trust in management has a significant impact on safety at the industry level (Conchie and Donald 2006), and in organizations where employees can report errors and near misses without fear to be blamed for them, trust is also found to promote the safety climate (Reason 1998). This means that trust in addition to mediate the relationship between safety climate and outcome may influence the safety climate directly. Pre-existing trust between employees and management seems to be central to effective offshore safety modification programs (Fleming and Lardner 2001). Trust between employees and managers is also found to be critical to the success of behavioural safety within the nuclear industry, also a high-risk one (Cox et al. 2004). Another study claims that the provision of safe operations needs clear communication between offshore employees and management, even if it is of negative character, otherwise the hiding of specific information will lead to the impairing of the problem (Conchie and Burns 2008). If employees trust their leaders, they believe in the information they are receiving because they evaluate it cognitively (Luria 2010). Thus, they are more likely to reach the same conclusions about safety and its importance as the management communicates. It is also essential to develop social coherence based on trust and reciprocity. A relevant example in this context is reported by Grøn and Svendsen (2013, p. 191):

Within the shipping sector, take the example of a captain who is two-faced and says that safety is his top priority, while in reality he encourages the crew to cut corners. As this is gradually discovered by crew members, general distrust, conflicts and lack of coordination and cooperation on board may well arise and destroy social capital.

In light of the argumentation above, our hypothesis (H4) is that employees' trust in their managers is positively related to safety.

Trust (and low conflict) among seafarers is associated with superior safety performance (Theotokas and Progoulaki 2007) and is also recognized as the most important factor for safety at local installations (Conchie and Donald 2006). Our hypothesis (H5) is therefore that trust among seafarers is positively related to safety. 
Procedures and control constitute an important feature of the shipping industry and its way to increase safety. Control and trust are found to be both substitutes and complements (Nooteboom 2002); in the words of Möllering (2015, p. 171), "You need control to manage risks. Nevertheless, if you have more trust, there can be less control. But blind trust, without any control at all as something to fall back on, is not wise". Trust therefore seems to somewhat reduce the importance of control for safety reasons, and the level of trust may be too high. Trust is also identified to have a situational optimal level: This optimal level is "the degree of fit between trust levels and interdependence levels in a given firm-stakeholder relationship" (Wicks et al., 1999, p. 105). Interdependence is here "the degree to which both parties are dependent on each other to achieve their desired outcomes" (Wicks et al. 1999, p. 104). National cultures with high levels of power distance (Hofstede 1984), e.g. Philippines, may have very high level of trust to their leader. Too high level of trust may lead to reducing the responsibility of the employees (Conchie et al. 2006), and may also have a negative influence on safety because of groupthink and overreliance on others (Conchie and Donald 2006; Erdem 2003; Janis 1982). Our hypothesis (H6) is therefore that an optimal level of trust exists onboard, and because of the high-risk environment, all seafarers onboard are highly interdependent on each other related to their joint safety. Therefore, the optimal level of trust is relatively high.

\subsection{Obstacles to trust in the shipping industry}

Theory directly concerned with obstacles to trust-building is scarce. Our point of departure, therefore, is more indirectly the assumption that lack of factors and processes that contribute to building interpersonal trust may function as obstacles to trust.

The employment practice in the shipping industry is generally dual: The senior officers are employed by the shipping company, while the rest of the crew is employed by crewing agencies. By owning 56\%, the OECD countries have the largest share of ownership of the world fleet in tonnage (Berg et al. 2013). The employment policy of European ship owners is to employ "their own nationals as senior officers (Master, Mate and Chief Engineer) and third world seafarers for the remaining positions" (Theotokas and Progoulaki 2007, p. 384). The crewing agencies are often located in other parts of the world than the shipping company (Berg et al. 2013; Grøn and Svendsen 2013). This practice implies several obstacles to trust: (1) it affects cognitive trust because, due to so called paper mill educators that give certificates without training and increased risk of faked certificates, it creates challenges to secure the crews' qualifications (Berg et al. 2013), (2) multinational subordinate crew have less favorable conditions than the senior officers (Berg et al. 2013) and (3) the people working onboard are hired by two different companies and hence represent two different systems with different visions and cultures. Shared vision seems to increase trust (Abrams et al. 2003; Argyres 1999; Tsai and Ghoshal 1998), especially in terms of cognitive trust (McAllister 1995). Therefore, "the explanations to the lack of trust are partially located in the nature of seafarers' employment relations" (Bhattacharya 2012, p. 18) which makes the element of trust in the shipping industry even more challenging. Our hypothesis (H7) is therefore that the dual employment practice in the shipping industry constitutes an obstacle to interpersonal trust. 
A low level of trust between the onshore managers and their seafaring colleagues is identified in several studies, and what hindered the development of trust between them was the physical distance between onshore and offshore (Bhattacharya 2012; Xue 2012). This low level of trust may lead to under-reporting of accidents and near misses. The managers felt that the seafarers were breaking company policies and falsifying accidents reports, while the seafarers feared that reported accidents could be used against them, thus increasing the risk of losing their jobs (Bhattacharya 2012). Knowledge sharing between onshore and the captains is among other important factors for safety, because company managers are responsible to communicate the company's vision regarding safety to the captains (Flin and Yule 2004). Because of this and that interpersonal contact is required to build cognitive and affective trust, our hypothesis (H8) is that, the physical distance between onboard, the crewing agency and onshore constitutes an obstacle to interpersonal trust.

Due to the pressure of finding cheaper seafarers, the national "quality requirements for subordinate crews' competence is lowered" (Berg et al. 2013, p. 14; Theotokas and Progoulaki 2007), which also affects the competence part of cognitive trust. Our hypothesis (H9) is therefore that reduced competence requirements in the shipping industry constitutes an obstacle to interpersonal trust.

A study of trust among crew members found that the subordinate crew has a very fragmented working environment, moving frequently from ship to ship and from one international working crew to another (Grøn and Svendsen 2013). The senior officers, employed by the shipping company, often work on the same ship for a long period. The crew members prefer to continue working with the same crew to establish bonding and bridging, which will strengthen the company's profitability and productive cooperation, as well as decrease the accident rate (Grøn and Svendsen 2013). In light of the argumentation above, our hypothesis (H10) is that interpersonal trust constitutes an important aspect of such bonding and bridging, and that frequent reorganization of the crew constitutes an obstacle to interpersonal trust.

Nowadays, the crew is generally multicultural, which means that "people from many countries and/or cultures interact regularly" (Adler and Gundersen 2008, p. 17). In an extensive literature review of the impact on crews on maritime safety, Berg et al. (2013 p. 5) concluded that "Intercultural cooperation, communication, fatigue and the language skills of a seafarer are the most important issues that contribute to maritime safety on the individual level". The behavioural assumptions underlying the cognitive trust-building processes are governed by cultural norms and values (Doney et al., 1998; McAllister 1995). Since cultural norms and values tend to vary across national cultures, the process of trust-building is heavily dependent on culture, and there is also a greater chance of interpersonal trust-building between people sharing the same norms and values (Doney et al. 1998). Hofstede (1984) identified significant differences on several dimensions of national culture. The most important one is power distance, which indicates how much inequality exists between bosses and subordinates. Most subordinate crew are currently from the Philippines and China (Berg et al. 2013), and most senior officers from Europe (Theotokas and Progoulaki 2007). Asia and Southern Europe represent cultures with high power distance, while Northern Europe represents cultures with low power distance. Therefore, the multicultural nature of the crew onboard often entails different cultural dimensions that challenge interpersonal trustbuilding in general, and trust-building between managers and crew in particular. 
Furthermore, the language differences also constitute an obstacle to trust. Our hypothesis (H11) is therefore that multiculturalism constitutes an obstacle to interpersonal trust.

\section{Method}

This study is a combination of a literature review and an empirical pilot study. The literature review contributes to demonstrate the current state of knowledge within the research area, and to connect the study to the wider theoretical picture (Gill and Johnsen 2002). Since it is deemed an appropriate design to answer "why" and "what" questions, and also because the phenomenon of trust and safety needs to be understood within the (shipping industry) context, an in-depth single case study with qualitative data is chosen for the empirical pilot study. A case study also renders extensive analysis of a single case and enables the use of multiple data collection methods (Bhattacherjee 2012). Although this is not a classical hypothesis-testing study, we have decided to organize parts of the literature review as a hypothesis-building activity. The purpose with the pilot study is to check if the hypotheses are supported, to look for practical examples, to look inductively for aspects of the research question outside the literature review and to prepare for further studies to test the hypothesis quantitatively.

\subsection{Empirical data collection}

The empirical data was collected during the spring of 2014 through semistructured interviews, observation and secondary data sources. The informants constitute a stratified sample of key informants, onshore managers and offshore seafarers, selected according to occupation, culture, age and relevant experience. Six in-depth interviews with a semi-structured interview guide were performed with three Norwegian onshore managers and three Latvian seagoing captains. The plan was to additionally interview one or two Filipino captains, but that did not turn out to be feasible, as they did not wish to participate in the project. As the interviewer was a Latvian female researcher, this may be due to cultural differences, gender issues and/or fear to speak out.

The interviews with the managers were performed in English, while the interviews with the captains were performed in Latvian. Quotations from the Latvian interviews have been translated into English by the researchers. Sixteen hours of observation were carried out in the company's onshore office with the use of an observation guide and by taking observation notes: Three middle managers - the HR, QA and safety managerwere carefully followed; this was combined by an observation of the premises, artifacts and office workers in their natural environment, e.g. listening to their phone talks. The main themes in the observation guide were the general atmosphere and openness, how they refer to the ships and their crew (respect, trust, proudness) and their safety focus. All the interviews were recorded and fully transcribed; so were also the observation notes. Sources of secondary data are the company's Master's and Management Review 2013 (the main events of the year, and a review of accidents and injuries), the company's web-page and ten accident reports, randomly selected from the archive of the shipping company. The archive is organized ship-wise; to obtain a random sample, 
each second ship was selected, and when several accident reports were found, the most recent one was chosen.

\subsection{Data analysis}

The 37 literature contributions was first analyzed and coded deductively into categories, e.g. "trust as a general precondition for safety". Then the literature was coded inductively into other categories, e.g. "situational matters", "reorganizing crew" and "outsourcing of crew manning". The transcribed interviews and the observation notes from the pilot study were first analyzed and coded deductively (Miles et al., 2014) in accordance with the interview and the observation guides, and then distributed according to different categories. For example, the question "To what degree does the onshore part of the company trust the offshore part of the company?" may entail that in the following text the category "trust level" is likely to be found. This category, however, would not be limited to this text only, because the informants used narrative descriptions all along. Consequently, categories, or deductive codes, such as "trust level" and "cultural differences" were created. In addition, inductive coding (Miles et al. 2014) of the interviews and observations was performed, and new categories were created such as "trust gap" and "extra link".

\subsection{The pilot case}

A shipping management company was selected as case because of its fragmented vertical and horizontal hierarchy (Grøn and Svendsen 2013). The company was incorporated in 1974 by a family with a long shipping history. It is still a family business within the same family, and the headquarters and the chartering department are located in Norway. It employs about 490 people, about 440 offshore seafarers and about 50 onshore office employees. The seafarers are mainly Latvian, Russian and Filipinos. The manning of the ships is outsourced to a crewing agency located in Riga (Latvia) and Manila (Philippines) and is followed up by the Norwegian HR department. The company has currently specialized in the transportation of liquid products, and operates a fleet consisting of 17 chemical/product tankers, varying from 13 to 19,000 dwt. It has some few considerably sized important customers, and its main routes are within the North West European trade.

\section{Empirical findings}

\subsection{Trust and safety}

All the data sources indicate that the company seems to be very committed to safety both on the onshore and on the offshore side. This is illustrated by two comments by the captains: "I like it a lot in this company, there is no compromise in safety"; "Cargo should be delivered on time, safely and effectively, how can we separate it?" The managers in the office agreed. One of them shared a rich experience in the industry as well as an understanding of the human life's value with regard to safety: "Safety is how we are working. You might save the fraction of a minute, but we have to send you 
home in a coffin". Additionally, safety posters were observed on the walls in the office, and the company's web-page also testifies to safety commitment; even if it is very minor evidence, it still points in the same direction. Safety is mentioned in the company's written vision and values, the vision says that the company "shall provide our customers with safe, reliable \& cost efficient tanker transportation" and the values that "we are hands-on, caring of our integrity and accountable for each other and responsible in all our activities" (Company's web-page 2017.01.04.). The company's commitment to safety is also supported by the statistics, as they are, e.g., improving dramatically in reporting of near misses, from 14 in 2003 to 78 in 2007 and all 659 in 2012.

One of the company's current challenges is to keep the costs and the accident rate down. The "lost time injuries frequency" was zero in 2013, and the aim is to keep it there. Because the cost of experienced officers is increasing rapidly, the number of such officers onboard has been reduced. Furthermore, the officers have suggested raising the entry requirements for new Filipino employees, as they are frequently perceived as not competent enough. More experienced personnel will increase the costs, but - on the other hand - a smaller amount of experienced personnel may influence the quality and increase the risk of critical situations.

The interviews of the captains started with a general discussion of trust, then all of them immediately mentioned its importance and the connection between trust and safety: "The more trust we have for each other, the more we are connected, the calmer they are and I am, and everything works better. This is a very important part of the system which also relates to safety", and "It is impossible to organize your work on board without trust, and you cannot do everything by yourself, trust is necessary". These quotations show that trust is not only the basis for effective work, but it is also strongly related to safety.

The captains also expressed the notion that lack of willingness to be vulnerable (which according to the definition means lack of trust) may cause different safety problems, as is evident from the following quotations: "They are hesitating to call the captain to the bridge, and are afraid to show that they don't know, or do not understand, something"; "If he didn't correct the navigational map, or didn't say that the ship is drifting, and there are shallow waters, or there is a dangerous ship coming towards us...and he is lost, he makes something up...and makes the wrong decision". All the Latvian captains supported that on the basis of their observations it is common for Filipino workers to hide important details of the ongoing issues. At the same time, it is unfortunately unknown to us if Filipinos are sharing such details among each other.

This lack of willingness to be vulnerable is a safety problem because it may lead to wrong decisions, as exemplified by one of the captains:

I also had another situation. A very bad situation. If you only think what costs could arise because of his actions... He didn't inform me and made his own decision. But the company will ask the captain first... And I cannot say I don't know. We discussed our task with him and how we have to do it. But he made his own decision. I had to lie to other parties just to get out of this situation.

All the captains argued that they encourage speaking up immediately about critical work situations. Furthermore, each and every one confirmed that they have no 
objections to be called to the bridge any time of the day, because losses may be more significant than the bothering of a captain.

Ten accident reports were randomly selected from the archive of the shipping company. The archive is organized ship-wise; to obtain a random sample, each second ship was selected, and when several accident reports were found, the most recent one was chosen. According to the analysis of these report, three out of ten accidents happened due to lack of communication, and two accidents out of ten happened under pilotage.

The managers in the office also provided strong arguments in support of the influence of trust on safety:

If I don't trust those on board, I might not take in their information clearly enough, or I might not put enough weight on their information, and I might take wrong decisions here in the office. They will suffer on board or we will get bad results, normally it is the last one. Conversely, if they don't trust us in the office, then perhaps they might not tell us information that could be really important, information that we could learn from, that could help us do a better job, or enable us to effect experience transfer to other ships, as not all the ships need to do the same mistake.

It was also stated that trust is very much dependent on performance and handling of safety procedures, just as sloppy, inaccurate work leads to lack of trust; therefore, trust based on performance is important for the company in this case. This kind of trust, along with trust based on competence, was explicitly addressed by the people on the offshore side:

Trust is necessary, but there are different levels of trust... It is impossible to trust everybody at the same level. Everything depends on the qualification of the person. Some have higher qualification, some have lower, therefore trust to someone is higher, and to someone else is lower. Someone you control less, someone you control more.

When the new employee arrives he is unknown to me. There comes a CV with appraisal, it looks like the grades are good but it doesn't mean anything. Time goes by and my opinion about this person is developing. Let's say, it is 2nd or 3rd mate, to whom I can delegate my rights. It is written that the rights can be delegated immediately but it is not always so. Before I can be sure, I have to form an opinion about this person. How he works and what his attitude to his duties is. You start trusting slowly. Start to understand it after a while.

How the person is following the procedures is very important for me and my colleagues, and this is how opinion is built about the person.

When stepping onboard, new unqualified employees trigger an initial lack of trust generated by their lack of competence. Thus, the crew's competence may also be seen as an intervening variable. The captains express worries about cutting on qualified personnel, with safety and quality breaches as the consequence. The data showed, 
however, that the company is somewhat avoiding to put weight on this opinion. This might be somewhat contradictory to the captains' arguments about the company's safety commitment, which may be interpreted in more than one way. One interpretation is that the captains' arguments on safety commitment were mostly normative. Another interpretation is that the company's commitment to safety is dominated by direct safety concerns and not by more indirect links like personnel competence. A third interpretation is that the captains' message about this is not made clear enough towards the company.

An outline of the main findings from the literature review and the additional findings from the pilot study about the ways in which safety onboard is influenced by interpersonal trust, is provided as a framework in Table 1.

\subsection{Obstacles to trust}

The multicultural environment onboard was clearly addressed in the empirical data. The crew onboard consists of Latvian captains, Latvian or Filipino chief officers and Filipino rating. It was supported by all the interviewees that there is a great gap among these cultures, and the findings showed that this creates certain difficulties related to trust and safety. One of the captains told us:

Before I didn't know what was happening on board. Now it is getting better. There is this fear (Filipino people have) - 'I will not say and it should be ok' - but when something comes out on the surface, it is scary to learn what they were hiding.

All the captains highlighted the problem lying in not speaking up and how that might lead to errors.

Another major pattern in our interpretation of the findings is that there seems to be a disequilibrium in the trust level between the onshore and the offshore part of the company: The office managers seem to trust their captains more than the captains trust them. The pattern of this "trust gap" appears further in the interview with one of the captains: "I don't believe that they think about seafarers... They are busy with commerce" and "If you have never worked at sea, you will never understand the sea life, and the one who is working there". One of the managers also admitted that seafarers probably do not trust the office-based part:

We learned from this case... several of the superintendents also received feedback that 'Oh, we think that if we contacted the office nothing would happen' and 'If we contacted the office we might have problem ourselves' and so on. That's a clear indication that they don't trust... they don't trust what kind of actions would be taken by the company, if they contacted us with this kind of serious information.

The office managers refer to the captains with pride, and it is evident that they do know them and respect them. For instance, in the course of the observation in the office, a random phone conversation was heard where one office employee addressed a captain in a respectful and very friendly manner. 
In the building of trust between the company and the crew, the crewing agency emerged as an "extra link":

So if someone has some issues or some questions or something, I guess most of them will bring it up with the girls from Manila [at the crewing agency] and discuss it with them. And if it's a bigger issue they would come to us. Or they might be advised by the crewing agency - 'oh, I think you should discuss it with them'. Very often I can see that the crewing agency is passing it forward, like 'OK we have questions like this and this, what would you recommend if this is ok?', but that of course is not building the trust between us and seafarers because there's an extra link there.

This extra link may contribute to the trust gap as well.

An outline of the main findings from the literature review and the additional findings from the pilot study about which main obstacles to interpersonal trust that can be found in the shipping industry is provided as a framework in Table 2.

\section{Discussion}

\subsection{Trust and safety}

Most of the different aspects of the relationship between trust and safety in this study, e.g. communication, collaboration, knowledge sharing, human errors, to believe in information, safety concern, commitment to safety, safety culture, calling the captain to the bridge and under-reporting, are matters that may influence safety indirectly as a precondition. It is therefore likely to assume that interpersonal trust is influencing safety as an indirect factor. If it is a mediating variable, according to the findings of Kath et al. (2010), or something else, can, however, not be derived from this study. Hypothesis 1 is therefore partly supported.

The theoretical findings of trust as a general precondition for safety onboard, as presented in Table 1, were supported by the pilot study, especially those related to knowledge sharing, asking for advice and learning from experiences like mistakes and near misses. Several of the theoretical findings of the importance of trust between managers and employees, as presented in Table 1, were also supported. That lack of crews' trust to the captain influences safety because it may lead to fear of showing lack of knowledge, fear of informing and asking for advice and fear of calling the captain to the bridge. Such fear may again lead to human errors as avoidance of decision-making, or wrong decision-making altogether. Therefore, if trust between managers and employees runs low, human errors seem to increase, which gives support for hypothesis 2 and 4.

One of our interpretations of the findings is that the onshore managers seem to trust the captains more than the captains trust them. The trust gap between the onshore and offshore part may be somewhat explained by the captains often being "the ones to blame" - the interviewees made it clear that there is trust between the parties, but only until an emergency situation happens: "When I am at the office, my boss invites me to drink beer, acting like a friend, but I think if something happens, they will forget that we had this friendly relationship", or "I know that even if we have friendly relationship with the owner, when I do something wrong, he will be angry". The interviews showed that this kind of 
Table 1 In what way is safety on board influenced by interpersonal trust?

\section{Topic}

Trust as a general precondition for safety

Situational matters

$$
\begin{gathered}
\text { employees } \\
\text { emst between }
\end{gathered}
$$

\section{Key findings}

Interpersonal trust is a prerequisite for knowledge-sharing and learning.

Interpersonal trust is essential in sharing knowledge in a reciprocal way, as it is a significant factor in both sharing and absorbing tacit knowledge, which is crucial for the creation of new knowledge.

Interpersonal trust is an important prerequisite for asking for advice.

Interpersonal trust enables organizations to capture, reuse and share information and lessons learned from past mistakes with employees and newcomers.

Trust is a major aspect of accuracy of work.

It is essential to develop social coherence based on trust and reciprocity.

Communication and cooperation are important for maritime safety, and there seem to be a connection between interpersonal trust, communication and cooperation.

Interpersonal trust may be an indirect factor, or mediating variable, influencing safety-related organizational outcomes positively.

In a crisis, people need trust in order to reduce the complexity they are facing.

Trust may be more important for safety in weak situations, than in strong situations.

About $75-96 \%$ of the accidents in the shipping industry happen due to human errors, e.g. incorrect decision, improper action, or lack of action at all. One reason for incorrect decision may be lack of knowledge sharing; one type of lack of action is not asking for advice. Interpersonal trust is an important prerequisite for knowledge sharing and asking for advice.

Trust enhances care for the safety of employees, and if employees trust the management, they are more likely

to share the manager's opinion about the importance

of safety, and to believe in the information they are receiving.

Trust facilitates open and safe communication.

Management's commitment to safety promotes trust from workers. Trust between workmates is the most important factor for safety at local installations.

Trust and low conflict among seafarers is associated with superior safety performance.

Managers' trust and concern about crew's safety and encouraging of safe behaviors contribute to increase safety onboard.

Trust between employees and managers is critical to the success of behavioral safety.
References

Matzler et al. 2011

Krogh, Ichijo and Nonaka 2000

Nonaka 1994

Abrams et al. 2003

Dirks 2000

Galford and Drapeau 2002

Grøn and Svendsen 2013

Berg et al. 2013

Dirks and Ferrin 2002

Hardin 2002

Kath et al. 2010

Luhmann 1979

Dirks and Ferrin 2002

Rothblum et al. 2002

Abrams et al. 2003

Krogh et al. 2000

Luria 2010

Reason 1998

Conchie and Donald 2006

Theotokas and Progoulaki 2007

Cox et al. 2004

Lu and Tsai 2008

Slovic 2001

Nooteboom 2002

Möllering 2015

Conchie and Donald 2006

Wu, Chang, Shu, Chen, and Wang 2011

Flin and Yule 2004

Conchie and Burns 2008

Bhattacharya 2012

Pilot study

Pilot study 
Table 1 (continued)

\begin{tabular}{|c|c|c|}
\hline Topic & Key findings & References \\
\hline & $\begin{array}{l}\text { Trust is an important factor in risk management, } \\
\text { because } \\
\text { it affects judgements of risk and benefit, as } \\
\text { well as different forms of cooperation. } \\
\text { Trust seems to somewhat reduce the importance } \\
\text { of control for safety reasons. } \\
\text { Trust in management has a significant impact on } \\
\text { safety at } \\
\text { the industry level. } \\
\text { Onshore company managers are identified as the } \\
\text { most significant predictive factor for } \\
\text { promoting a safety culture that elicits safe } \\
\text { behaviors. } \\
\text { Knowledge sharing between onshore and the } \\
\text { captains is essential because company } \\
\text { managers are responsible to communicate the } \\
\text { company's vision for safety to the captains. } \\
\text { The provision of safe operations needs clear } \\
\text { communication between offshore employees } \\
\text { and management } \\
\text { A low level of trust between from the captains to } \\
\text { the onshore managers may lead to } \\
\text { under-reporting of accidents and near misses } \\
\text { The onshore managers seem to trust the captains } \\
\text { more than the captains trust them } \\
\text { Lack of trust from the crew to the captain } \\
\text { influences safety because it may lead to fear } \\
\text { of showing lack of knowledge, fear of } \\
\text { informing and asking for advice and fear of } \\
\text { calling the captain to the bridge. }\end{array}$ & \\
\hline Trust among seafarers & $\begin{array}{l}\text { Trust (and low conflict) among seafarers is } \\
\text { associated with superior safety performance. } \\
\text { Trust between work mates is recognized as the } \\
\text { most important factor for safety at local } \\
\text { installations. }\end{array}$ & $\begin{array}{l}\text { Theotokas and Progoulaki } \\
2007 \\
\text { Conchie and Donald } 2006\end{array}$ \\
\hline Optimal level of trust & $\begin{array}{l}\text { An optimal level of trust exists, and because all } \\
\text { seafarers are highly interdependent on each } \\
\text { other related to their joint safety, the optimal } \\
\text { level of trust onboard is relatively high } \\
\text { Too much trust may lead to reducing the } \\
\text { responsibility of employees } \\
\text { Too high level of trust may also have a negative } \\
\text { influence on safety because of groupthink and } \\
\text { overreliance on others. }\end{array}$ & $\begin{array}{l}\text { Wicks et al. } 1999 \\
\text { Conchie et al. } 2006 \\
\text { Conchie and Donald } 2006 \\
\text { Erdem } 2003 \\
\text { Janis } 1982\end{array}$ \\
\hline
\end{tabular}

relationship is perceived as the norm. Therefore, it is possible to conclude that the relationship between ships and shore is perceived by the captains as a mixture of professional (cognitive trust) and friendly (affective trust) relationship. The fact that all three captains stated that they feel very comfortable in this company may, however, reduce the gap between ship and shore. The disequilibrium of trust between onshore and onboard emerged as a possible new contribution to theory that needs to be tested in a further study. 
Table 2 What are the main obstacles to interpersonal trust in the shipping industry?

Topic
Dual employment practice

Physical distance

Reduced competence requirements

Reorganizing crew

Multiculturalism

\section{Key Findings}

Similar visions and cultures contribute to trust. When the people working onboard are hired by two different companies, they represent two different systems with different visions and cultures, which hinder trust.

Reduced possibility for quality control of crew education affects cognitive trust.

Frequent close interactions contribute to build both cognitive and affective trust.

The physical distance between onshore and offshore makes frequent close interactions difficult, and thus hinders trust-building.

The physical distance between onshore, offshore and the manning agency hinders frequent close interactions among the three actors, and thus hinders trust-building.

Reducing the requirements for competence and qualifications for the crew hinders cognitive trust onboard and between onshore and offshore.

Reducing number of officers decreases the extent to which the ship officers trust the onshore office - which hinders cognitive trust.

Building trust takes time and reorganizing of crew between each voyage hinders long-time relationships

Shipping is a multicultural industry.

Multiculturalism among the crew onboard and between the different parts of the company (onshore vs offshore) challenges trust-building because of different cultures and languages.

\section{Reference}

Bhattacharya 2012

Berg et al. 2013

Abrams et al. 2003

Bhattacharya 2012

Gausdal 2012

Xue 2012

Grøn and Svendsen 2013

Berg et al. 2013

Theokas and Progoulaki 2007

Pilot study

Grøn and Svendsen, 2013

Adler and Gundersen 2008

Hofstede 1984

Doney et al., 1998

McAllister 1995

The link between interpersonal trust and safety in strong or weak situations, and how trust among seafarers influence safety, is not covered in the pilot study, hypothesis 3 and 5 are therefore supported by theory only.

In the pilot study, $20 \%$ of the accidents in the randomly selected reports happened under pilotage. This may have different explanations. One explanation is that pilotage takes place in risky waters, another explanation is that the captain is trusting the pilot too much, resulting in a mismatch between the level of trust and the level of interdependence between the parties, leading to a not optimal level of trust. Hypothesis 6 may therefore be somewhat supported by the pilot study.

\subsection{Obstacles to trust}

The dual employment practice as an obstacle to trust was supported by the pilot study as the manning agency as an extra link between the onshore and offshore part of the company. Hypothesis 7 is therefore somewhat supported by the pilot study. 
The challenge of the great physical distance between onshore, the ship and the crewing agency was indirectly supported by the pilot study as an obstacle to communication, collaboration and interaction, all prerequisites for building trust. Hypothesis 8 is therefore somewhat supported by the pilot study.

The pilot study shows that to save costs, the company has reduced the number of experienced officers onboard; at the same time, the competence requirements for new Filipino crew members appear to be low. These two factors are resulting in employees with a decreased level of qualifications and competence, which also constitutes an obstacle to trust, as competence and qualifications are necessary to build characteristicbased trust. The data show that competence and qualifications within the shipping company, both onshore and offshore, are regarded as the prerequisite for trust development and safety keeping. This corresponds with the thought of Mayer et al. (1995), who argue that ability is considered as one of the antecedents to trust, and competence is deemed a synonym to ability. Hypothesis 9 is therefore somewhat supported by the pilot study.

Regarding obstacles to trust, the theoretical findings that the shipping industry seems to foster unstable interpersonal relations because of the reorganization of the crew between each voyage, as presented in Table 2, was supported by the pilot study. Such unstable relations make it difficult to learn about peoples' competence and trustworthy behaviour, which is necessary to build characteristic-based trust. Unstable relations also make it almost impossible to build process-based trust, which demands that people interact and collaborate over time. Hypothesis 10 is therefore supported by the pilot study.

The last dimension of obstacles to trust is multiculturalism. Hofstede (1984) comprehensive work on cultural differences, including power distance, which is used in this study and widely applied theoretically and practically, is also heavily discussed (Jones 2007). The criticism is, e.g. that recent research has identified culture to be fragmented across national lines, while Hofstede sees a domestic population as a homogeneous whole, that Hofstede's data is from one company only (IBM), and that the data is too old to be valuable for the modern globalized world (Jones 2007). In a recent evaluation of Hofstede's work, Jones (2007 p. 7) concluded, however, that "it remains the most valuable piece of work on culture for both scholars and practitioners". The theoretical findings of multiculturalism as an obstacle to trust was indeed supported by the pilot study: This multiculturalism exist between onshore and offshore because of different organizational sub-cultures and among the crew because of different nationalities with different languages and different levels of power distance. One example is the issue with not speaking up, which may be seen as a specific attitude connected to this particular culture; thus, multiculturalism influences trust and safety. In line with Jones (2007), hypothesis 11 is therefore supported by the pilot study.

A summary of the discussion is provided in Table 3.

This study also has some limitations. The existing literature of the influence of trust on safety onboard is scarce. The chosen definition of trust and the focus on cognitive and affective trust also make some limitations, as other definitions and other frameworks may give somewhat different explanations. The empirical sample is very small and lacks one important nationality onboard, the Filipinos, and subordinate crew. The topic is quite sensitive, especially for those working offshore: In their view, information about accidents could compromise their competence or carrier, so there could be reason 
Table 3 Discussion summary

No. Hypothesis

In what way is safety on board influenced by trust?

1 Interpersonal trust may be an indirect factor, or mediating variable, influencing safety related organizational outcomes positively

2 Interpersonal trust may influence human errors negatively

3 Interpersonal trust is positively influencing safety in weak situations

4 Employees trust in their managers is positively related to safety

5 Trust among seafarers is positively related to safety

6 An optimal level of trust exists onboard, and because of the high-risk environment, all seafarers onboard are highly interdependent on each other related to their joint safety. Therefore, the optimal level of trust is relatively high

What are the main obstacles to interpersonal trust in the shipping industry?

7 The dual employment practice in the shipping industry constitutes an obstacle to interpersonal trust

8 The physical distance between onboard, crewing agency and onshore constitutes an obstacle to interpersonal trust

9 Reduced competence requirements in the shipping industry constitutes an obstacle to interpersonal trust

10 Frequent reorganization of the crew constitutes an obstacle to interpersonal trust.

11 Multiculturalism constitutes an obstacle to interpersonal trust.

- A disequilibrium of trust between onshore and onboard may exist

\section{Supported by Comments}

pilot study

Partly

supported

Supported

Not included in the pilot study

Supported

Not included in the pilot study

Somewhat supported

Somewhat supported

Somewhat supported

Somewhat supported

Supported

Supported

New finding from the pilot study

for holding back essential details. The interviewer's personal influence and different aspects regarding the informants may bias the answers from the semi-structured interviews. Furthermore, the interviews with the office managers were performed in English, which is the second language for both parts. The interviews with the captains were translated from Latvian into English in the course of the analysis, and it is possible that part of the meaning was lost or slightly modified. Semi-structured interviews and observations also include lack of standardization of the data-collecting process. Finally, Norway is considered a high-trust society (Newton 2001), the empirical findings from the pilot study may therefore not be generalized to low-trust societies.

To confirm and test the framework and the hypotheses empirically, further studies are needed - especially of the qualitative type. These studies should preferably be confirmed in societies with different trust levels - to test the framework and to confirm the conclusions. Ideally, a multiple case study with quantitative data from, e.g., 
shipping companies from four different nations with different levels of power distance and general trust would be preferable.

\section{Concluding remarks}

The answer to the first part of the research question is that interpersonal trust from employees to managers and among seafarers seems to be a prerequisite and an indirect factor, or mediating variable, that influence safety-related organizational outcomes positively and seems to reduce human errors. Interpersonal trust seems, moreover, to be most valuable in weak situations, which means situations that are not critical and when no exact guidance or incentives to behave in a particular way are needed. An optimal level of trust exists onboard, and because of the high-risk environment, this optimal level of trust is expected to be relatively high. The answer to the second part of the research question is that the main obstacles to trust within the shipping industry seem to be the dual employment practice, the physical distance between onboard, crewing agency and onshore, the reduced competence requirements, the frequent reorganization of the crew and multiculturalism.

This study has theoretical and practical implications. The theoretical implications are the new framework indicating how safety onboard is influenced by interpersonal trust, and the identification of the main obstacles to interpersonal trust in the shipping industry. Moreover, the 11 developed hypotheses, and another study indicating that trust may be the missing piece in the safety puzzle, contributes to the trust and the safety theories. The practical implications regard the acknowledgement of interpersonal trust influencing safety, as well as an emphasis on trust in both offshore and onshoreoffshore relationships. Furthermore, the recruiting policy in shipping companies, the dual employment practice as well as the challenges with multiculturalism. Finally, another practical implication regards which obstacles for trust should be removed.

Acknowledgements This work was supported by the Norwegian MARKOM2020 project. The authors are grateful for helpful comments from the editor and the anonymous reviewers.

Open Access This article is distributed under the terms of the Creative Commons Attribution 4.0 International License (http://creativecommons.org/licenses/by/4.0/), which permits unrestricted use, distribution, and reproduction in any medium, provided you give appropriate credit to the original author(s) and the source, provide a link to the Creative Commons license, and indicate if changes were made.

\section{References}

Abrams LC, Cross R, Lesser E, Levin DZ (2003) Nurturing interpersonal trust in knowledge-sharing networks. Acad Manag Exec 17(4):64-77

Adler N, Gundersen A (2008) International Dimensions of Organizational Behavior (Fifth ed.): South-Western Cengage Learning

Argyres NS (1999) The impact of information technology on coordination: evidence from the B-2 "Stealth" bomber. Organ Sci 10(2):162-180

Berg N, Storgård J, Lappalainen J (2013) The impact of ship crews on maritime safety. The Centre for maritime studies, University of Turku, Turku

Bhattacharya S (2012) Sociological factors influencing the practice of incident reporting: the case of the shipping industry. Employee Relations 1:4-21 
Bhattacherjee A (2012) Social science research: principles, methods, and practices. Textbook collections 3. Global text project. Florida, US

Conchie SM, Burns C (2008) Trust and risk communication in high-risk organizations: a test of principles from social risk research. Risk Anal 28(1):141-149. doi:10.1111/j.1539-6924.2008.01006.x

Conchie SM, Donald IJ (2006) The role of distrust in offshore safety performance. Risk Anal 26(5):11511159. doi:10.1111/j.1539-6924.2006.00822.x

Conchie SM, Donald IJ, Taylor PJ (2006) Trust: missing piece(s) in the safety puzzle. Risk Analysis: An International Journal 26(5):1097-1104. doi:10.1111/j.1539-6924.2006.00818.x

Cox S, Jones B, Rycraft H (2004) Behavioural approaches to safety management within UK reactor plants. Saf Sci 42:825-839

Dirks KT (2000) Trust in leadership and team performance: evidence from NCAA basketball. J Appl Psychol 85(6):1004-1012

Dirks KT, Ferrin D (2002) The role of trust in organizational setting. Organ Sci 12:450-467

Doney PM, Cannon JP, Mullen MR (1998) Understanding the influence of national culture on the development of trust. Acad Manag Rev 23(3):601-620

Erdem F (2003) Optimal trust and teamwork. From groupthink to teamthink Work study 52:229-233

Fleming M, Lardner R (2001) Behaviour modification programmes establishing best practice. Offshore Technology Report 48

Flin R, Yule S (2004) Leadership for safety: industrial experience Quality and safety in health care, 13(SUPPL. 2), ii45-ii51. doi: 10.1136/qshc.2003.009555

Galford R, Drapeau AS (2002) The trusted leader. Simon \& Schuster, New York

Gausdal AH (2012) Trust-building processes in the context of networks. Journal of Trust Research 2(1):7-30

Gill J, Johnsen P (2002) Research methods for managers, 3rd edn. Paul Chapman, London

Grøn S, Svendsen G (2013) "Blue" social capital and work performance: anthropological fieldwork among crew members at four Danish international ships. WMU J Marit Aff 12(2):185-212. doi:10.1007/s13437013-0041-X

Hardin R (2002) Trust and trustworthiness. Russel Sage Foundation, New York

Hofstede G (1984) Culture's consequences: international differences in work-related values (cross cultural research and methodology). Sage, London

Janis IL (1982) Groupthink: psychological studies of policy decisions and fiascoes, 2nd edn. Houghton Mifflin, Boston

Jones ML (2007) Hofstede - culturally questionable? Paper presented at the Oxford. Business \& Economics Conference, Oxford

Kath LM, Magley VJ, Marmet M (2010) The role of organizational trust in safety climate's influnece on organizational outcomes. Accid Anal Prev 42:1488-1497

Krackhardt D (1992) The strength of strong ties: the importance of Philos in organizations. In: Nohira N, Eccles RG (eds) Network and organizations: structure, form and action. Harvard Business School Press, Boston, pp 216-239

Krogh G v (1998) Care in knowledge creation. Calif Manag Rev 40(3):133-153

Krogh G v, Ichijo K, Nonaka I (2000) Enabling knowledge creation: how to unlock the mystery of tacit knowledge and release the power of innovation. Oxford University Press, Oxford

Lencioni P (2002) The five dysfunctions of a team. Jossey-Bass, San Francisco

Lewis JD, Wiegert A (1985) Trust as a Social Reality. Social Forces 63(4):967-985

Lu C-S, Tsai C-L (2008) The effects of safety climate on vessel accidents in the container shipping context. Accid Anal Prev 40(2):594-601

Luhmann N (1979) Trust and power. John Wiley, Chichester

Luria, G. (2010). The social aspects of safety management: trust and safety climate. Accident Analysis \& Prevention, 42(4), 1288-1295. Retrieved from

Matzler K, Renzl B, Mooradian T, Krogh G, Mueller J (2011) Personality traits, affective commitment, documentation of knowledge, and knowledge sharing. The International Journal of Human Resource Management 22(2):296-310

Mayer RC, Davis JH, Schoorman FD (1995) An integrative model of organizational trust. Acad Manag Rev 20(3):709-734

McAllister DJ (1995) Affect- and cognition-based trust as foundation for interpersonal cooperation in organizations. Acad Manag J 38(1):24-59

Miles MB, Huberman AM, Saldaña J (2014) Qualitative data analysis: a methods sourcebook (3rd ed.). Sage, Thousand Oaks

Mischel W (1977) On the future of personality measurement. Am Psychol 32(4):246-254. doi:10.1037/0003066X.32.4.246 
Möllering G (2006) Trust: reason, routine, reflexitivity. Elsevier, Oxford

Möllering G (2015) The practical wisdom of trust: an interview with Bart Nooteboom. Journal of Trust Research 5(2):170-183

Naphiet, J., \& Ghoshal, S. (1998) Social capital, intellectual capital and the organizational advantage. The Academy of Management Review, 23(242-266).

Newton K (2001) Trust, social capital, civil society, and democracy. International Political Science Review 22(2):201-214. doi:10.1177/0192512101222004

Nielsen D (1999) Deaths at sea — a study of fatalities on board Hong Kong-registered merchant ships (198695). Saf Sci 32(2-3):121-141. doi:10.1016/S0925-7535(99)00016-8

Nonaka I (1994) A dynamic theory of organizational knowledge creation. Organ Sci 5(1):14-37

Nooteboom B (2002) Trust. Forms, foundations, functions, failures and figures. Edward Elgar Publisher Limited, Cheltenham

Norwegian_maritime_authority. (2016). Accident statistics business vessels 2015 (Notat Ulykkesstatistikk næringsfartøy 2015) (pp. 1-11)

Reason, J. (1998). Achieving a safe culture: theory and practice Work \& Stress, 12(3), 293-306.

Ring PS, Van De Ven AH (1994) Developmental processes of cooperative interorganizational relationships. Acad Manag Rev 19(1):90-118

Rothblum AM, Wheal D, Withington S, Shappel SA, Wiegmann DA (2002) Improving incident investigation through inclusion of human factors (pp. 6-7)

Rotter JB (1971) Generalized expectancies for interpersonal trust. Am Psychol 26(5):443

Theotokas I, Progoulaki M (2007) Cultural diversity, manning strategies and management practices in Greek shipping. Marit Policy Manag 34(4):383-403

Tsai WP, Ghoshal S (1998) Social capital and value creation: the role of intrafirm networks. Acad Manag J 41(4):464-476

Wagenaar WA, Groeneweg J (1987) Accidents at sea: multiple causes and impossible consequences. International Journal of Man-Machine Studies 27(5-6):587-598

Wicks AC, Berman SL, Jones TM (1999) The structure of optimal trust: moral and strategic implications. Acad Manag Rev 24(1):99-116

Wu TC, Chang SH, Shu CM, Chen CT, Wang CP (2011) Safety leadership and safety performance in petrochemical industries: the mediating role of safety climate. J Loss Prev Process Ind 24(6):716-721. doi:10.1016/j.jlp.2011.04.007

Xue C (2012) Communication and its role in influencing shipboard occupational health and safety management in Chinese shipping. (Master). Cardiff University, Cardiff

Zand DE (2016) Reflections on trust and trust research: then and now. Journal of Trust Research 6(1):63-73

Zohar D (1980) Safety climate in industrial organizations: theoretical and applied implications. J Appl Psychol 65:96-102

Zucker LG (1986) Production of trust: institutional sources of economic structure, 1840-1920. Res Organ Behav 8:53-111 